\title{
Paclitaxel-Coated or Uncoated Devices: Significant Differences in Patient Populations and Mortality Led to Study Incomparability
}

Chenyang Zhang and Guosheng Yin

\begin{abstract}
Authors' affiliations:
Department of Statistics and Actuarial Science, University of Hong Kong, Hong Kong
\end{abstract}

\section{Corresponding author:}

Guosheng Yin, PhD

Patrick S C Poon Endowed Professor and Head

Department of Statistics and Actuarial Science

The University of Hong Kong

Pokfulam Road, Hong Kong SAR, China

Email: gyin@hku.hk

Tel: 852-3917-8313; Fax: 852-2858-9041

Conflicts of interest: The authors declare no potential conflict of interest. 
medRxiv preprint doi: https://doi.org/10.1101/2021.01.29.21250732; this version posted February 1, 2021. The copyright holder for this preprint (which was not certified by peer review) is the author/funder, who has granted medRxiv a license to display the preprint in perpetuity.

It is made available under a CC-BY 4.0 International license.

\section{Abstract}

2 The SWEDEPAD trial reported an unplanned interim analysis to show no difference in

3 the mortality rate between the paclitaxel-coated and uncoated groups (Nordanstig et al.,

4 2020), which contradicts the long-term risk of paclitaxel-coated devices claimed by a

5 meta-analysis (Katsanos et al., 2018). However, there existed significant differences in

6 mortality rates between the SWEDEPAD trial and the trials included in the meta-analysis,

7 which were caused by significant differences in the patient populations. As a result, the

8 SWEDEPAD trial and meta-analysis results are not directly comparable. An updated

9 meta-analysis including the SWEDPEPAD trial and all studies in the meta-analysis

10 (Katsanos et al., 2018) shows marginal differences in mortality rates between the

11 paclitaxel-coated and control groups at two years with Bayesian relative risk (RR) 1.39

12 (95\% credible interval $(\mathrm{CrI})[1.01,2.39])$ and frequentist RR 1.16 (95\% confidence

13 interval (CI) $[0.99,1.36])$ and differences in mortality rates during the entire follow-up

14 period with Bayesian RR 1.29 (95\% CrI [1.01, 1.72]) and frequentist RR 1.13 (95\% CI

$15[0.99,1.28])$ under random-effects models. Given the relatively short follow-up thus far

16 in the SWEDEPAD trial (with a mean follow-up of 2.49 years) and the paclitaxel-coated

17 risk being long-term (e.g., 4 or 5 years), the interim results on the risk of paclitaxel-

18 coated devices reported by the SWEDEPAD trial warrant further investigation. 
medRxiv preprint doi: https://doi.org/10.1101/2021.01.29.21250732; this version posted February 1, 2021. The copyright holder for this preprint (which was not certified by peer review) is the author/funder, who has granted medRxiv a license to display the preprint in perpetuity.

It is made available under a CC-BY 4.0 International license .

\section{$1 \quad 1 \quad$ Introduction}

2 The SWEDEPAD trial ${ }^{1}$, which are investigating paclitaxel-coated versus uncoated

3 devices in patients with peripheral artery disease (PAD), was temporarily suspended on

4 December 2018 due to the potential long-term risk of paclitaxel-coated devices reported

5 by a meta-analysis. ${ }^{2}$ An unplanned interim analysis of the SWEDEPAD trial showed no

6 difference in the mortality rate between the paclitaxel-coated and uncoated groups at one

7 year with a hazard ratio (HR) of $1.03(95 \%$ CI $[0.77,1.37])$ or during the entire follow-up

8 period with an HR of $1.06(95 \%$ CI $[0.92,1.22])$. Based on these results, it was decided

9 to resume enrollment in the SWEDEPAD trial on March 23, 2020. However, Figure 2 of

10 the SWEDEPAD trial publication shows that the cumulative incidence curves of drug-

11 coated devices constantly stayed above those of uncoated either for the overall population

12 or subgroups of chronic limb threatening ischemia or intermittent claudication. ${ }^{1}$ The risk

13 of paclitaxel-coated devices is known to be of long term, ${ }^{2,3}$ while the SWEDEPAD trial

14 has so far had a mean follow-up of 2.49 years which is still relatively short for evaluating

15 long-term risk.

16

172 Methods and Results

\section{$18 \quad 2.1 \quad$ Baseline Differences in Patient Populations}

19 By pooling the numbers of deaths and patients from all studies included in the meta-

20 analysis, we treat the combined data as a mega-trial, ${ }^{2}$ and compare the differences in

21 mortality between the SWEDEPAD trial ${ }^{1}$ and mega-trial. For the paclitaxel-coated group,

22 we found significant differences in the all-cause death rates at one year with relative risk

23 (RR) $4.4(95 \%$ CI $[3.2,6.0])$ and during the entire study period with RR 3.7 (95\% CI [3.1, 
medRxiv preprint doi: https://doi.org/10.1101/2021.01.29.21250732; this version posted February 1, 2021. The copyright holder for this preprint (which was not certified by peer review) is the author/funder, who has granted medRxiv a license to display the preprint in perpetuity.

It is made available under a CC-BY 4.0 International license.

$14.5]$ ). For the uncoated group (control), the mortality rate differences between the

2 SWEDEPAD trial ${ }^{1}$ and mega-trial were also significant with RR 4.2 (95\% CI [3.0, 5.9])

3 at one year, and RR 5.7 (95\% CI [4.5, 7.2]) during the entire study period. All RRs

4 comparing the SWEDEPAD trial $^{1}$ and mega-trial ${ }^{2}$ are larger than 3.5 with p-values

5 smaller than 0.0001 , which could have attributed to incomparability between the

6 SWEDEPAD trial ${ }^{1}$ and the trials included in the meta-analysis ${ }^{2}$. There are significant

7 differences at the baseline in the patient populations between the SWEDEPAD trial and

8 trials in meta-analysis: the former had $35 \%$ intermittent claudication (IC) and 65\%

9 chronic limb threatening ischemia (CLTI) while the latter had 89\% IC and 11\% CLTI.

10 CLTI is an advanced stage of PAD. Compared with intermittent claudication, CLTI has a

11 negative prognosis within a year after the initial diagnosis, with a 1-year amputation rate

12 of approximately $12 \%$ and mortality rates of $50 \%$ at 5 years and $70 \%$ at 10 years. ${ }^{4}$ The

13 baseline prognosis difference could be a main cause of observed differences in mortality

14 rates between the studies.

\section{$16 \quad 2.2 \quad$ Updated Meta-Analysis}

17 We conducted an updated meta-analysis which included the SWEDEPAD trial ${ }^{1}$ and all

18 studies in the meta-analysis ${ }^{2}$. The number of deaths by two years of the SWEDEPAD

19 trial $^{1}$ was estimated by multiplying the estimated two-year cumulative incidence rate and

20 the total number of patients. For each study in the meta-analysis ${ }^{2}$, we took the results

21 with the longest follow-up as those for the entire study period. The R packages 'meta'

22 and 'bayesmeta' were used to formulate frequentist and Bayesian random-effects models,

23 respectively. 
medRxiv preprint doi: https://doi.org/10.1101/2021.01.29.21250732; this version posted February 1, 2021. The copyright holder for this preprint

2 As shown in Table 1, both frequentist and Bayesian random-effects models demonstrate

3 no difference in one-year all-cause death rates between paclitaxel-coated and uncoated

4 arms, indicating no short-term risk of paclitaxel-coated devices. At two years or during

5 the entire follow-up period, the frequentist random-effects model yields marginally

6 insignificant differences in all-cause death rates with two-year RR 1.16 (95\% CI [0.99,

7 1.36], $\mathrm{P}=0.063)$, and the entire follow-up RR 1.13 (95\% CI [0.99, 1.28], $\mathrm{P}=0.065$ ).

8 However, the Bayesian random-effects model yields an RR of 1.39 (95\% credible

9 interval $(\mathrm{CrI})[1.01,2.39])$ at two years and an RR of $1.29(95 \% \mathrm{CrI}[1.01,1.72])$ during

10 the entire follow-up period, which suggests significant risk of paclitaxel-coated devices

11 with longer-term follow-ups. The posterior probabilities for the death rate of the

12 paclitaxel-coated arm being higher than that of the control arm were around 0.98 at two

13 years and during the entire follow-ups, with Bayes factors larger than 40 . This provides

14 strong evidence for the long-term mortality risk of paclitaxel-coated devices.

\section{3. Conclusion}

17 The SWEDEPAD trial ${ }^{1}$ enrolled 2289 patients, which is about half of the total number of

18 patients included in the meta-analysis ${ }^{2}$. Although one study with such a large sample size

19 and insignificant results was added, the new meta-analysis still yields marginally

20 significant differences in the mortality rates at two years and during the entire follow-up.

21 Moreover, with a mean follow-up of only 2.49 years, the results of the SWEDEPAD trial

22 warrant further investigation, because the risk from paclitaxel-coated devices is long-

23 term. $^{5}$ 


\section{References}

21 Nordanstig J, James S, Andersson M, et al. Mortality with paclitaxel-coated

3 devices in peripheral artery disease. N Engl J Med 2020;383:2538-2546.

42 Katsanos K, Spiliopoulos S, Kitrou P, Krokidis M, Karnabatidis D. Risk of death

5 following application of paclitaxel $\square$ coated balloons and stents in the femoropopliteal

6 artery of the leg: a systematic review and meta $\square$ analysis of randomized controlled trials.

$7 \quad$ J Am Heart Assoc 2018;7:e011245.

83 Beckman JA, White CJ. Paclitaxel-coated balloons and eluting stents: is there a

9 mortality risk in patients with peripheral artery disease? Circulation 2019;140:1342-51.

104 Varu VN, Hogg ME, Kibbe MR. Critical limb ischemia. J Vasc Surg

$11 \quad 2010 ; 51: 230-41$.

125 Rocha-Singh KJ, Duval S, Jaff MR, et al. Mortality and paclitaxel-coated devices:

13 an individual patient data meta-analysis. Circulation 2020;141:1859-69. 
1 Table 1. Relative risk and interval estimates of the meta-analysis including the

2 SWEDEPAD trial $^{1}$ and all studies in the meta-analysis ${ }^{2}$.

\begin{tabular}{|c|c|c|c|c|}
\hline & & \multicolumn{3}{|c|}{ Follow-up period } \\
\hline & & One year & Two years & Entire follow-up \\
\hline \multirow[t]{2}{*}{ Frequentist } & Random-effects & $1.04[0.84,1.28]^{*}$ & $1.16[0.99,1.36]$ & $1.13[0.99,1.28]$ \\
\hline & $\mathrm{P}$ value & 0.713 & 0.063 & 0.065 \\
\hline \multirow[t]{2}{*}{ Bayesian } & Random-effects & $1.04[0.77,1.41]$ & $1.39[1.01,2.39]$ & $1.29[1.01,1.72]$ \\
\hline & $\begin{array}{l}\text { Posterior probability } \\
\text { of }(\mathrm{RR}>1)\end{array}$ & 0.613 & 0.978 & 0.980 \\
\hline
\end{tabular}

4 interval (Bayesian) in the brackets. 